\title{
VIABILIDADE DO BAÇO DE RATOS APÓS A LIGADURA SIMULTÂNEA DA ARTÉRIA E VEIA ESPLÊNICAS
}

\author{
SPLEEN VIABILITY AFTER THE SIMULTANEOUS SPLENIC ARTERY AND VEIN \\ LIGATION IN RATS
}

\author{
Danilo Nagib Salomão Paulo, TCBC-ES' ${ }^{1}$ Isabel Cristina Andreatta Lemos Paulo, ACBC-ES ${ }^{2}$; \\ Edson Ricardo Loureiro ${ }^{3}$; Fausto Edmundo Lima Pereira ${ }^{4}$; Luiz Sérgio Pereira Grillo Jr${ }^{5}$;
} Alcino Lázaro da Silva, TCBC-MG6

\begin{abstract}
RESUMO: Objetivo: A ligadura simultânea da artéria e veia esplênicas, com preservação do baço, é realizada em seres humanos, na pancreatectomia caudal, mas o efeito exato dessa ligadura sobre o baço não é bem conhecido. O objetivo deste trabalho foi verificar o efeito da ligadura dos vasos esplênicos principais no baço de ratos. Método: Foram operados 58 ratos Wistar, machos, variando entre 230 e $408 \mathrm{~g}$ de peso. Os animais foram divididos aleatoriamente em dois grupos: grupo 1, simulação $(\mathrm{N}=23)$, submetido à laparotomia e manipulação do baço; grupo $2(\mathrm{~N}=35)$ submetido à ligadura simultânea da artéria e veia esplênica. Todos os animais foram mortos 12 dias após a operação. O baço era retirado, pesado, fixado em formol a 4\%, incluído em parafina, e os cortes foram corados pela hematoxilina e eosina para exame microscópico. Resultados: O baço era normal em todos os animais do grupo 1 e em três dos 34 animais $(8,82 \%)$ do grupo 2. Ocorreu infarto branco parcial do baço em $91,18 \%$ dos animais do grupo 2 . O percentual médio de massa esplênica viável nos baços com infartos foi de $56,9 \pm 21,8 \%$. O aspecto histopatológico mostrou arquitetura preservada na porção não infartada, e neoformação conjuntivo-vascular cicatricial substituindo as áreas necrosadas. Conclusões: A ligadura simultânea da artéria e veias esplênicas resultou em infarto branco parcial do baço em $91,2 \%$ dos animais, com preservação mínima de $35 \%$ e média de $56,9 \%$ de massa esplênica viável. Na maioria dos animais que sofreram ligadura, o infarto se localizou na porção inferior do baço (Rev. Col. Bras. Cir. 2005; 32(1): 32-35).
\end{abstract}

Descritores: Baço; Infarto do baço; Ligadura; Ratos wistar.

\section{INTRODUÇÃO}

A esplenectomia total pode induzir a várias complicações, entre as quais a mais temida é a síndrome infecciosa pós-esplenectomia ${ }^{1-3}$. A sepse fulminante pós-esplenectomia foi destacada por King e Schumacker ${ }^{4}$ em 1952 e observada em 2,7\% dos esplenectomizados por O' $\mathrm{Neal}^{5}$. As complicações infecciosas pós- esplenectomia foram também observadas em animais de experimentação ${ }^{6-9}$. Além das complicações infecciosas, têm sido relatadas, após esplenectomia, alterações no metabolismo lipídico tanto em seres humanos ${ }^{10-12}$ quanto em animais de experimentação ${ }^{13-16}$. Por essas razões têm sido cada vez mais valorizadas as operações conservadoras sobre o baço, incluindo as ligaduras vasculares.

A ligadura da artéria esplênica é realizada como coadjuvante do tratamento do trauma esplênico ${ }^{17}$, no combate à hipertensão porta ${ }^{18} \mathrm{e}$ no aneurisma da artéria esplênica ${ }^{19}$. A ligadura simultânea da artéria e veia esplênicas, com preservação do baço, foi realizada na pancreatectomia caudal por via laparatômica ${ }^{20,21}$ e por via laparoscópica ${ }^{22}$, mas sem relatos detalhados das conse- qüências para o baço. Experimentalmente, a ligadura da artéria esplênica em ratos normais reduz a massa funcional do baço ${ }^{23}$, combate o hiperesplenismo induzido por ligadura da veia esplênica ${ }^{24,25} \mathrm{e}$ a hipertensão porta experimenta ${ }^{26}$. A ligadura isolada da veia esplênica no rato induz ao hiperesplenismo ${ }^{24}$. As consequiências para o baço da ligadura simultânea da artéria e da veia esplênicas não têm sido descritas. Por isso, decidiu-se investigar os efeitos da ligadura simultânea da artéria e veia esplênicas em ratos adultos, no $12^{\circ}$ dia de pós-operatório.

\section{MÉTODO}

Foram utilizados 58 ratos Wistar machos, provenientes do biotério da Emescam, com peso entre $230 \mathrm{~g} \mathrm{e} 408 \mathrm{~g}$. Os animais foram divididos, aleatoriamente, em dois grupos: grupo 1, 23 ratos, simulação; grupo 2, 35 ratos, submetidos à ligadura simultânea da artéria e veia esplênicas.

A manipulação dos animais atendeu às normas de pesquisa em animais, preconizadas pelo Colégio Brasileiro de Experimentação Animal (COBEA).

1. Professor Titular da Disciplina de Técnica Operatória e Cirurgia Experimental da Escola Superior de Ciências da Santa Casa de Misericórdia de Vitória-ES-EMESCAM.

2. Médica do Hospital Universitário Cassiano Antonio Morais-UFES (Universidade Federal do Espírito Santo); Mestranda em Cirurgia pela Faculdade de Medicina da Universidade Federal de Minas Gerais.

3. Professor Assistente da Disciplina de Técnica Operatória e Cirurgia Experimental da Escola Superior de Ciências da Santa Casa de Misericórdia de Vitória-ES-EMESCAM.

4. Professor de Patologia do Centro Biomédico da Faculdade de Medicina da Universidade Federal do Espírito Santo (UFES)

5. Aspirante a Oficial Médico Temporário do Exército Brasileiro.

6. Professor Titular de Cirurgia da Faculdade de Medicina da Universidade Federal de Minas Gerais (UFMG).

Recebido em 01/07/2004

Aceito para publicação em 30/09/2004

Trabalho realizado no Laboratório de Técnica Operatória e Cirurgia Experimental da Escola Superior de Ciências da Santa Casa de Misericórdia de Vitória-ES- EMESCAM. 


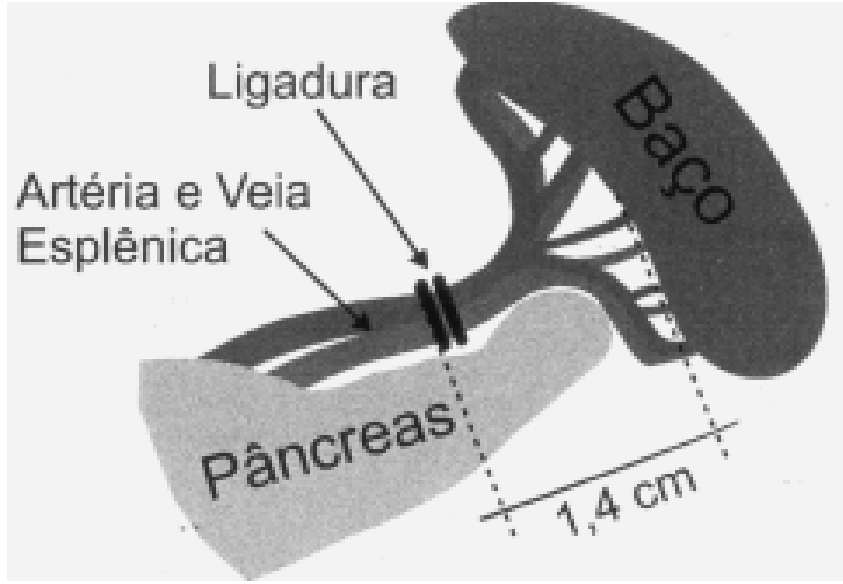

Figura 1 - Esquema mostrando os locais onde foram realizadas as ligaduras da artéria e da veia esplênicas do baço de ratos.

A anestesia dos animais foi inalatória com éter etílico. Em seguida realizou-se a depilação das paredes abdominal e torácica ventral. Fez-se a antissepsia com solução de álcooliodado e colocação de um campo operatório fenestrado para delimitar o local da laparotomia.

Nos animais do grupo 1, fez-se incisão longitudinal, mediana, com cerca de $2,5 \mathrm{~cm}$ de comprimento, iniciada $0,5 \mathrm{~cm}$ abaixo do processo xifóide, em direção ao púbis. Realizou-se o inventário da cavidade abdominal e manipulação do baço. A seguir suturou-se a parede abdominal em dois planos: peritônio e plano músculo-aponeurótico com mononylon 4-0, chuleio simples e a pele com mononylon 4-0, chuleio simples. Nos animais do grupo 2, o procedimento foi idêntico ao do grupo 1, acrescido de dupla ligadura simultânea da artéria e veia esplênicas, a cerca de 1,4 cm da borda hilar do baço (Figura 1). A seguir, suturou-se a parede abdominal de maneira idêntica à do grupo 1 . Os animais operados foram sacrificados no $12^{\circ}$ dia de pós-operatório com dose letal de éter etílico. Os animais foram pesados e era feita uma incisão em U invertido na parede abdominal seguida de exploração da cavidade. Foram anotados os aspectos das vísceras abdominais, presença de aderências e o aspecto do baço. Esse foi retirado, pesado, fotografado e avaliado o seu aspecto macroscópico. A seguir, foi fixado em formol a 4\%. Após a fixação, os baços eram pesados e, os do grupo 2, eram seccionados no limite entre a área infartada e a área preservada, e os dois fragmentos pesados separadamente, com precisão de $0,001 \mathrm{~g}$. O percentual médio de massa viável dos baços do grupo 2 foi calculado dividindo-se o peso da parte viável pelo peso ideal do baço para cada animal, multiplicando-se o resultado por 100. Foi obtida a média do percentual de massa viável do baço com o respectivo desvio padrão. $\mathrm{O}$ cálculo do peso ideal do baço foi feito utilizando-se a fórmula peso do baço $=-87,25+2,33$ x peso corporal, obtida a partir da análise de regressão linear dos pesos dos baços em função do peso corporal nos animais do grupo simulação (Figura 2). Os fragmentos do baço eram incluidos em parafina, e os cortes corados pela hematoxilina e eosina.

\section{RESULTADOS}

Houve no transoperatório um óbito por excesso de anestésico. Ocorreu, próximo ao apêndice xifóide, em um ani- mal, um sangramento que foi imediatamente controlado. Em outro animal houve, por trauma cirúrgico no fígado, pequeno sangramento que parou espontaneamente. Em um rato ocorreu no cólon uma pequena lesão que foi suturada. Não observamos nenhum tipo de infecção no pós-operatório nos dois grupos de animais.

Foram observadas aderências em todos os ratos. Nos animais do grupo 1, as aderências eram frouxas e em pequena quantidade e ocorriam entre o baço e a parede abdominal e o fígado. Nos animais do grupo 2 as aderências eram mais freqüentes, intensas e firmes e ocorriam entre o baço e o fígado, intestino delgado, cólon, estômago e rim esquerdo. Em alguns casos as vísceras aderentes envolviam totalmente o baço. Em alguns casos foi observado granuloma de corpo estranho em torno do fio utilizado para ligadura dos vasos esplênicos.

O baço tinha aspecto macroscópico normal em todos os animais do grupo 1 . No grupo 2 o baço se apresentou macroscopicamente normal em três dos 34 animais $(8,82 \%)$. Trinta e um ratos $(91,18 \%)$ apresentaram infarto branco. $\mathrm{O}$ infarto comprometeu predominantemente a porção inferior e em três casos ocorreu na porção média do baço ( Figura 3).

O percentual médio de massa esplênica viável foi de $56,9 \pm 21,8 \%$ nos 31 animais que apresentaram infarto. $\mathrm{O}$ valor mínimo do percentual de massa viável foi de $35 \%$.

A análise microscópica mostrou arquitetura normal nos baços do grupo simulação. Nos fragmentos preservados dos baços dos animais submetidos à ligadura simultânea da artéria e veia esplênicas, a arquitetura dos baços estava preservada. Havia acentuada hiperemia passiva da polpa vermelha, com sinusóides muito distendidos, deixando bem delimitada a polpa branca que tinha arquitetura normal. A quantidade de tecido linfático nos folículos e na bainha periarterial era aparentemente normal. Na zona marginal observou-se depósito acentuado de hemossiderina. A neoformação conjuntiva e vascular era evidente no limite entre o tecido preservado e o necrótico. Nas áreas infartadas observaram-se restos do tecido necrótico, com

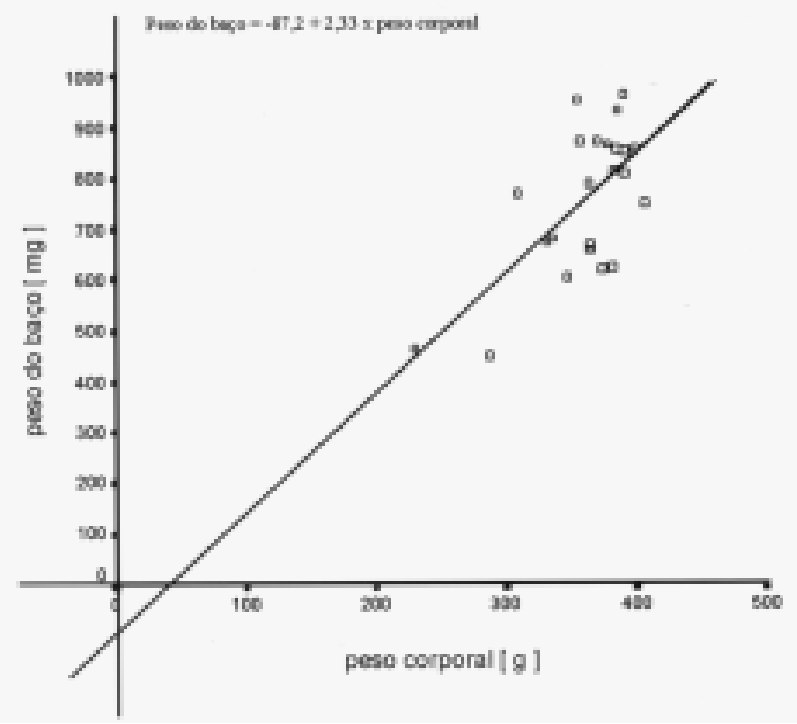

Figura 2 - Análise de regressão linear do peso do baço em função do peso corporal em 23 ratos falso-operados (laparotomia sem ligadura vascular esplênica). 


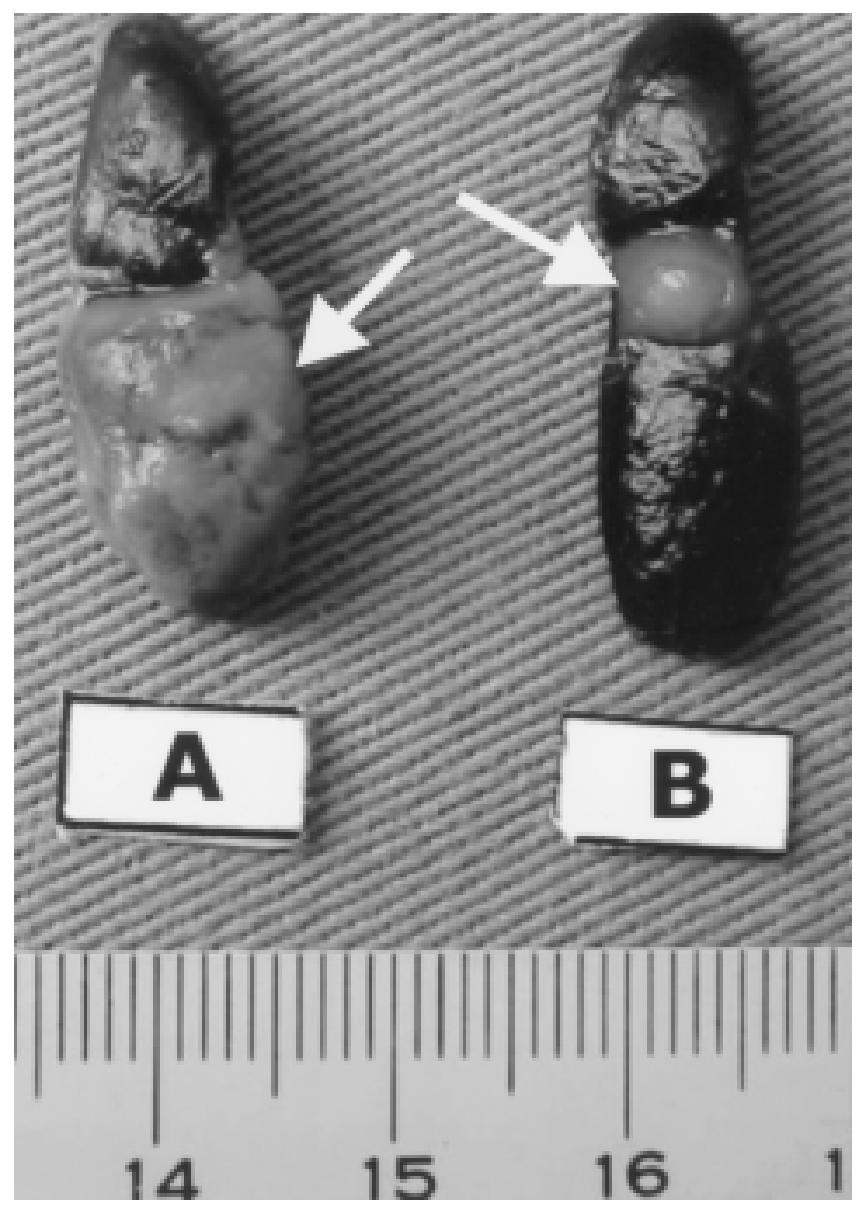

Figura 3 - Aspectos macroscópicos do baço após a ligadura simultânea da artéria e veia esplênicas. A - Infarto branco localizados na porção inferior(seta). B. Infarto branco localizado na porção média do órgão(seta).

extensa cariólise, e áreas focais com picnose nuclear e cariorexe e intensa neoformação conjuntivo-vascular cicatricial, partindo da cápsula. No tecido cicatricial havia quantidade variável de macrófagos carregados de hemossiderina (Figura 4).

\section{DISCUSSÃO}

A ligadura simultânea da artéria e veia esplênicas produziu infarto branco parcial em $91,18 \%$ dos animais, tendo ocorrido na metade inferior em $82,32 \%$ dos ratos. Isso demonstra que a circulação colateral para esse órgão é pouco eficaz após a ligadura realizada a cerca de $1,4 \mathrm{~cm}$ da face hilar. Por outro lado, a circulação colateral para a metade superior é bastante eficaz, uma vez que em todos os animais essa porção do baço se manteve viável. O pólo superior pode ser perfeitamente suprido por vasos esplenogástricos ${ }^{27}$. No entanto, como já foi mencionado, uma porção maior que o pólo superior esteve viável, demonstrando que, além dos vasos esplenogástricos, há outros que, no rato, suprem a referida porção. De fato durante o procedimento de ligadura vascular e no grupo simulação, observamos a presença de vasos que saíam da artéria esplênica, em pontos anteriores ao da ligadura, e se dirigiam à porção superior do baço (dados não mostrados). A ocorrência do infarto na porção média do baço, em três dos 34 casos, com preservação das áreas polares superior e inferior, mostra que a distribuição e a eficácia da circulação colateral não são uniformes. Nesses casos, permaneceram ramos colaterais que irrigam a área polar inferior e polar superior, impedindo a necrose nessas áreas.

O encontro de aderências firmes, freqüentes, envolvendo o baço e várias vísceras abdominais, após a ligadura simultânea da artéria e veia, confirma que a isquemia é um fator provocador de aderências ${ }^{28}$. No grupo simulação em que se manipulou o baço sem ligadura vascular as aderências eram frouxas.

No grupo 2 em que houve infarto parcial, o percentual de massa viável foi de 56,9\%. Esse percentual nos parece satisfatório para que o baço cumpra as suas funções, uma vez que há relatos de que a preservação de $25 \%$ de massa desse órgão é funcionalmente eficaz ${ }^{29}$. Assim, é possível que as temidas complicações infecciosas e alterações no metabolismo lipídico que ocorrem em seres humanos e em animais de experimentação, decorrentes da esplenectomia, não ocorram ou diminuam com as ligaduras vasculares. Estudos da função esplênica após a ligadura simultânea da artéria e veia poderiam confirmar esses aspectos.

É importante assinalar que não houve óbito que possa ser atribuído ao infarto esplênico no grupo de ratos submetidos à ligadura simultânea da artéria e veia esplênicas. Isso reforça a alegação de que esses vasos podem ser ligados em seres humanos sem problemas ${ }^{20-22}$, embora se saiba que, experimentalmente, a ligadura da artéria esplênica produz infarto da porção inferior do baço23.

Por outro lado, não se sabe ainda se a massa esplênica viável, após a ligadura, em períodos mais longos, poderia resultar em percentual maior de tecido viável, pois a porção infartada poderia sofrer hiperplasia regenerativa, a exemplo do que ocorre nos implantes esplênicos ${ }^{30}$.

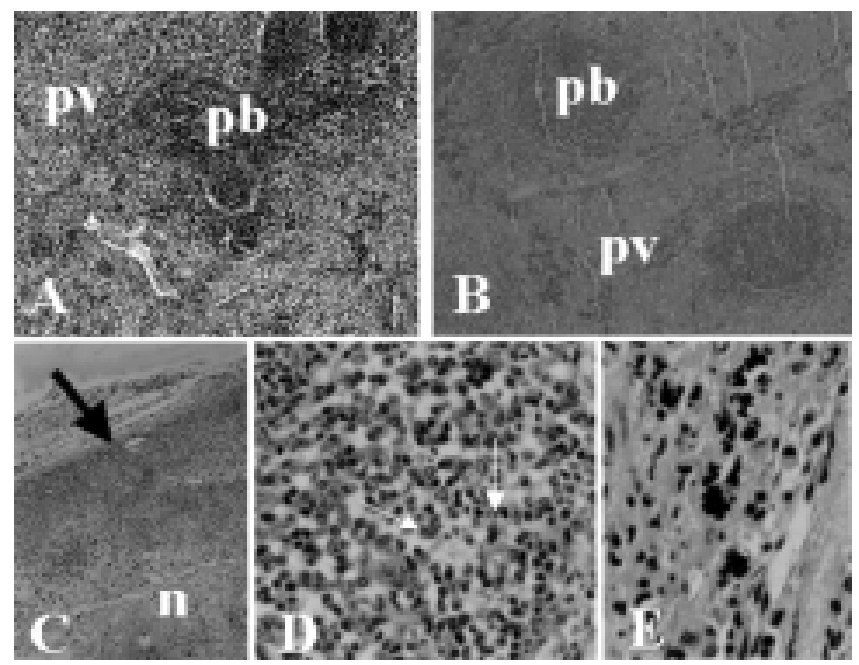

Figura 4 - Aspectos microscópicos do baço de ratos falso-operados ou submetidos à ligadura simultânea da artéria e veias esplênicas . A: Baço de animal falso-operado, mostrando arquitetura geral conservada (HE,100X). B, C, D e E: Baços de animais submetidos à ligadura da artéria e veia esplênicas. Em B (HE, 100X) observar intensa hiperemia da polpa vermelha ( $p v$ ) e folículos preservados ( $p b$ ). Em C (HE,100X) área infartada com fibrose cicatricial a partir da cápsula (seta) e restos de tecido necrótico (n). Em D (HE,400X) macrófagos da zona marginal cheios de hemossiderina (setas). Em E (HE, 400X) macrófagos no tecido cicatricial com grânulos de hemossiderina. 


\begin{abstract}
Background: The simultaneous ligation of splenic artery and vein without splenectomy is performed in caudal pancreatectomy in humans. The consequences of this procedure to the spleen are unknown. Here we report the effects of simultaneous ligation of splenic artery and vein twelve days after this vascular ligation in adults rats. Methods: Fifty eight adult male Wistar rats were randomized into 2 groups: group $1(N=23)$ sham operated, and group $2(N=35)$, simultaneous splenic artery and vein ligation. All animals were killed 12 days after surgery. The spleen was removed, weighted, fixed in $4 \%$ formalin, paraffin embedded and the sections stained with hematoxilyn and eosin. Results. The spleen was normal in all cases of the group 1 and in $8.82 \%$ of the group 2. Partial white infarct occured in $91.2 \%$ of the animals of group 2. The mean of the percentual viable mass in the infarcted spleen was $56.9 \pm 21.8 \%$. The microscopic examination showed normal splenic tissue in the preserved areas, with healing process of the necrotic areas. Conclusions. The simultaneous ligature of the splenic artery and vein resulted in partial infarct of the spleen in $91.2 \%$ of the animals, with a minimum of $35 \%$ preservation of splenic mass and a mean of percentual viable mass was $56.9 \%$ $\pm 21.8 \%$. The necrosis after vascular ligation occurred more frequently in the inferior portion of the spleen.
\end{abstract}

Key words: Spleen; Splenic infarction; Ligation; Rats, Wistar.

\section{REFERÊNCIAS}

1. Green JB, Shackford SR, Sise MJ, et al. - Late septic complications in adults following splenectomy for trauma: a prospective analysis in 144 patients. J Trauma,1986,26(11):9991004.

2. Di Cataldo A, Puleo S, Li Destri G, et al. - Splenic trauma and overwhelming postsplenectomy infection. $\mathrm{Br} \mathrm{J}$ Surg,1987,74(5):343-345.

3. Pimpl W, Dapunt O, Kaindl H, et al. - Incidence of septic and thromboembolic-related deaths after splenectomy in adults. $\mathrm{Br}$ J Surg, 1989,76(5):517-521.

4. King H, Shumacker HB - Splenic studies. Ann Surg, 1952,136:239-242.

5. O'Neal BJ, McDonald JC - The risk of sepsis in the asplenic adult. Ann Surg,1981, 194(6):775-778.

6. Morris DH, Bullock FD - The importance of the spleen in resistance to infection. Ann Surg, 1919,70:513-521.

7. Grosfeld JL, Ranochak JE - Are hemisplenectomy and/or primary splenic repair feasible? J Pediatr Surg,1976,11(3):419-424.

8. Goldthorn JF, Schwartz AD, Swift AJ, et al - Protective effect of residual splenic tissue after subtotal splenectomy. J Pediatr Surg,1978,13(6D):587-590.

9. Anderson R, Alwmark, Bengmark S - Outcome of pneumococcal challenge in rats after splenic artery ligation or splenectomy. Acta Chir Scand,1986,152:15-17.

10. Aviram M, Brook JG, Tatarsky I, et al. - Increased low-density lipoprotein levels after splenectomy: a role for the spleen in cholesterol metabolism in myeloproliferative disorders. Am J Med Sci,1986,291(1):25-28.

11. Sugihara T, Yawata Y - Observations on plasma and red cell lipids in hereditary spherocytosis. Clin Chim Acta, 1984,137(2):227-232.

12. Robinette CD, Fraumeni JF - Splenectomy and subsequent mortality in veterans of the 1939-45 war. Lancet, 1977,2(8029):127-129.

13. Asai K, Kuzuya M, Naito M, et al. - Effects of splenectomy on serum lipids and experimental atherosclerosis. Angiology, 1988,39(6):497-504.

14. Fatouros M, Bourantas K, Bairaktari E, et al. - Role of the spleen in lipid metabolism. Br J Surg, 1995,82(12):1675-1677.

15. Paulo DNS, Lázaro da Silva A - Lipídios plasmáticos após esplenectomia total e parcial em cães. Rev Col Bras Cir, 2001,28(3):264-270.

16. Silva MM , Jamel N, Refinetti RA, et al. - Papel do baço no perfil lipídico - Estudo Experimental. ABCD Arq Bras Cir Dig, 2002,15(2):121-124.
17. Conti S - Splenic artery ligation for trauma. An alternative to Splenectomy. Am J Sug, 1980,140(3):444-448.

18. Orozco H, Mercado MA, Martinez R, et al. - Is splenectomy necessary in desvascularization procedures for treatment of bleeding portal hypertension? Arch Surg 1998,133(1):36-8.

19. Abbas MA, Stone WM, Fowl RJ, et al. - Splenic artery aneurysms: two decades experience at Mayo Clinic. Ann Vasc Surg, 2002,16(4):442-449.

20. Warshaw AL - Conservation of the spleen with distal pancreatectomy. Arch Surg, 1988,123(5):550-553.

21. Gramática L, Lada PE, Gramática L, et al. - Conservação do baço durante a pancreatectomia córporo-caudal. Rev Col Bras Cir,1995, 22(4):227-229.

22. Ueno T, Oka M, Nishihara K, et al. - Laparoscopic distal pancreatectomy with preservation of the spleen. Surg Laparosc Endosc Percut Tech, 1999,9(4):290-293.

23. Witte CL, Witte MH, Renert W, et al. - Splenic artery ligation in selected patients with hepatic cirrhosis and in SpraqueDawley rats. Surg Gynecol Obstet, 1976,142(1):1-12.

24. Witte CL, Corrigan JJ, Witte MH et al. - Splenic artery ligation in experimental hypersplenism. Surgery,1976,80(5):581-585.

25. Sahin M, Tekin S, Aksoy F, et al. - The effects of splenic artery ligation in an experimental model of secondary hypersplenism. J R Coll Surg Edinb, 2000,45(3):148-152.

26. Lin PW, Shan YS - Effects of splenectomy and splenic artery ligation on the portal presure in portal hypertensive rats. J Surg Res, 1992, 53(6):621-624.

27. Petroianu A, Ferreira VL, Barbosa AJ - Morphology and viability of the spleen after subtotal splenectomy. Braz J Med Biol Res, 1989,22(4):491-495.

28. Ellis $\mathrm{H}$ - The aetiology of post-operative abdominal adhesions. An experimental study. Br J Surg,1962,49(1):10-16.

29. Campos Cristo MB - Esplenectomias parciales sistematizadas. Prensa Méd Argent, 1959,46:2189-2192.

30. Marques RG. Auto Implante esplênico em rato: regeneração morfológica e função fagocitária. Dissertação (Doutorado). Belo Horizonte. Universidade Federal de Minas Gerais, 2001, 104p.

Endereço para correspondência:

Danilo Nagib Salomão Paulo

Rua Santa Rita de Cássia, 777

Bairro de Lourdes

29042-753 - Vitória-ES 